\title{
Introducing the physician associate role in Ireland: Evaluation of a hospital based pilot project
}

\author{
Pauline Joyce*1, Roderick S. Hooker ${ }^{2}$, Denni Woodmansee ${ }^{1}$, Arnold DK Hill ${ }^{1}$ \\ ${ }^{1}$ Royal College of Surgeons in Ireland School of Medicine, Ireland \\ ${ }^{2}$ Health policy consultant, Ridgefield, WA, USA
}

Received: January 6, 2019

DOI: $10.5430 /$ jha.v8n3p50
Accepted: February 12, 2019 Online Published: May 24, 2019

URL: https://doi.org/10.5430/jha.v8n3p50

\begin{abstract}
Objective: Ireland has medical workforce challenges and a growing demand for services. One strategy is to include Physician Associates (PAs) in healthcare settings. A pilot study was undertaken with PAs recruited from North America and the United Kingdom to work in a large Dublin teaching hospital.

Methods: Four PAs were deployed on surgical services. Communication with the hospital staff preceded their employment. A series of interviews were undertaken at the beginning [2015] and end [2017] of the project. Data collection included surveys and interviews with staff and PAs.

Results: Despite a series of communications about the employment of PAs a lack of awareness among hospital staff prevailed. This presented a challenge for the PAs to assume their role and for staff to bring them on board. Once on board those staff who worked with the PAs found their role beneficial in terms of continuity of care and skillset. Recommendations for inclusion of PAs in any new employment should include a more robust stakeholder engagement and promulgation throughout the wider healthcare system.

Conclusion: Attitudes about the adoption of the PA have come slowly when first introduced in a country and Ireland seems no exception. At the same time communication lessons were learned about introducing a new health provider role in Irish society.
\end{abstract}

Key Words: Surgery, Physician assistant, Canada, United States, Patient satisfaction, Acceptance, Survey, Policy, Impact, Value for money

\section{INTRODUCTION}

The challenges in moving forward health reform where there are long waiting lists, even for operations that demand some urgency, is frustrating, particularly for the patient. Despite Ireland spending $7.8 \%$ of GDP (2016) on healthcare, long waiting lists, even for operations that demand some urgency persist. Ireland, together with the UK and Sweden, have been rated as having the worst patient feedback on accessibility/waiting time problems among the 35 countries ranked by the Euro Health Consumer Index.${ }^{[1]}$ All residents in Ire- land are entitled to treatment in public hospitals. Those with low income (approximately 36\%) are issued a medical card and receive care free of charge. Others pay a nominal fee. Alongside the public healthcare system, Ireland has a voluntary private health insurance market. This is primarily supplementary in nature, with some complementary cover. The supplementary element of private health insurance in Ireland provides cover for hospital services, while the complementary element provides partial reimbursement of fees for day-to-day medical expenses. The take-up rate private

*Correspondence: Pauline Joyce; Email: pjoyce@rcsi.ie; Address: RCSI School of Medicine, Ireland. 
health insurance in Ireland is $45 \%$ of the population. ${ }^{[2]}$ The public-private mix has been the centre of debate in Ireland with overlap between public and private healthcare. Mounting pressure on the government's health budget, with more costs directed to patients themselves, along with rising premiums in private health insurance, are challenges facing Irish society. ${ }^{[3]}$ Despite a commitment in 2001, by the Irish government, to increase the number of hospital beds, a majority of which were for the public sector, a $34 \%$ increase in beds was seen in the private sector, as distinctly different from $3 \%$ in the public sector. The focus on healthcare tends to change, depending on which political party is in power. In 2016 a joint healthcare committee across the political spectrum was undertaken. ${ }^{[4]}$ This committee developed consensus on a long-term policy direction for Ireland's healthcare system to ensure universal access to an affordable, universal, singletier healthcare system in which patients are treated promptly on the basis of need rather than ability to pay. ${ }^{[4]}$ However, the workforce planning issues to fulfil this policy direction remain a contentious issue. Doctors are leaving Ireland once they are qualified, due to long working hours, poor conditions and uncertain career progression, ${ }^{[5,6]}$ with $6.4 \%$ of doctors who exited from the medical register in $2015 .{ }^{[7]}$ The number of doctors registered in Ireland in 2013 was 2.7 per 1,000 people, which was lower than the Organisation for Economic Co-operation and Development (OECD) average of 3.3 doctors. ${ }^{[8]}$ An opportunity to explore other healthcare roles such as the Physician Assistant (PA) in use in North America and PA in the UK was undertaken.

This project examined the PA role in the Irish hospital setting. There are a number of reasons driving this PA implementation. There is over-dependence by the clinical teams on Non Consultant Hospital Doctors (NCHDs), particularly nontraining/service grade NCHDs, compared to international norms. NCHDs include all postgraduate medical trainees (interns through senior residents). The number of Irish and EU medical graduates doubled from 370 in 2006 to 730 by 2015, in line with national targets; yet there have only been modest increases in the numbers of doctors enrolled in postgraduate training programmes since 2011. At the same time, the pace of recruitment of doctors from medical schools outside of Ireland to non-training posts greatly exceeds the rate of recruitment to training posts. ${ }^{[7]}$ These recruitment challenges impact continuity of patient care, particularly at change-over times in January and July each year. Finally the need to improve European Working Time Directive (EWTD) compliance became a major driver for this project. EWTD came into law in 2004 making it unlawful for doctors in training to work more than 48 hours per week. ${ }^{[9]}$ The US responded to the reduction in residents' hours with expanding the em-

Published by Sciedu Press ployment of PAs. ${ }^{[10,11]}$ The result has been a major shift of responsibilities to the PA across a number of hospital settings improving training and reducing consultant work load. At the time of this pilot project in 2017, there were specific concerns in the Health Service Executive (HSE), Ireland's governing body for its public health service, that $77 \%$ of non-training NCHDs were International Medical Graduates (IMGs). ${ }^{[12,13]}$ This practice is challenging, from the Irish Medical Council's perspective (the regulator for doctors in Ireland), when dealing with standards of practice, language and communication issues. According to the WHO Global Code $^{[14]}$ IMGs should enjoy opportunities and incentives to strengthen their professional education, qualifications and career progression, on the basis of equal treatment with the domestically trained health workforce. However, there are limited training posts to fulfil this code.

We report on an innovative project aimed at addressing Ireland's medical workforce challenges using a hospital's budget forecast. As an exploratory project the intent was to deliver service improvements on a cost neutral basis with the potential to generate savings through reduced NCHD overtime and improvements in EWTD compliance. A mixed method evaluation of the project was undertaken. The policy implications are presented in the context of national and international challenges. Notwithstanding the global shortage of healthcare staff, including doctors ${ }^{[15]}$ and nurses, ${ }^{[16]}$ the importance of a strong business case around the right skill mix for patient care is discussed. The business case, for the PA role, included drivers and outcomes within the current challenges in the healthcare system, benefits unique to the PA role for the system, and a cost analysis. The learning from undertaking this project amidst political, economic and organisational constraints and realities is discussed. Key insights which can influence policy development at a national and international level are presented.

\section{MeTHODS}

\subsection{Design}

Evaluation, as a form of systematic inquiry, occupies an increasingly place in public policy making. ${ }^{[17]}$ Calls for accountability through evaluation research have increased the demand for measurements of performance. ${ }^{[18]}$ While evaluation can be a significant contributor to quality presenting the evidence does not necessarily guarantee that those in authority will heed the outcomes of evaluation and take corrective action. Evaluation research is intended to the effectiveness and effects of a programme or project. ${ }^{[19]}$

As in this project the Irish PA study is underpinned by the Value for Money framework, based on the Logic Model of Evaluation. ${ }^{[20]}$ In this model we focused on the Inputs, Ac- 
tivities, Outputs and Outcomes (see Figure 1) of the project. outputs and results in the logic model investigating efficiency, In this part of the project we focused on staff attitudes to effectiveness and impact.

the introduction of the PA role. The data reflects activities,

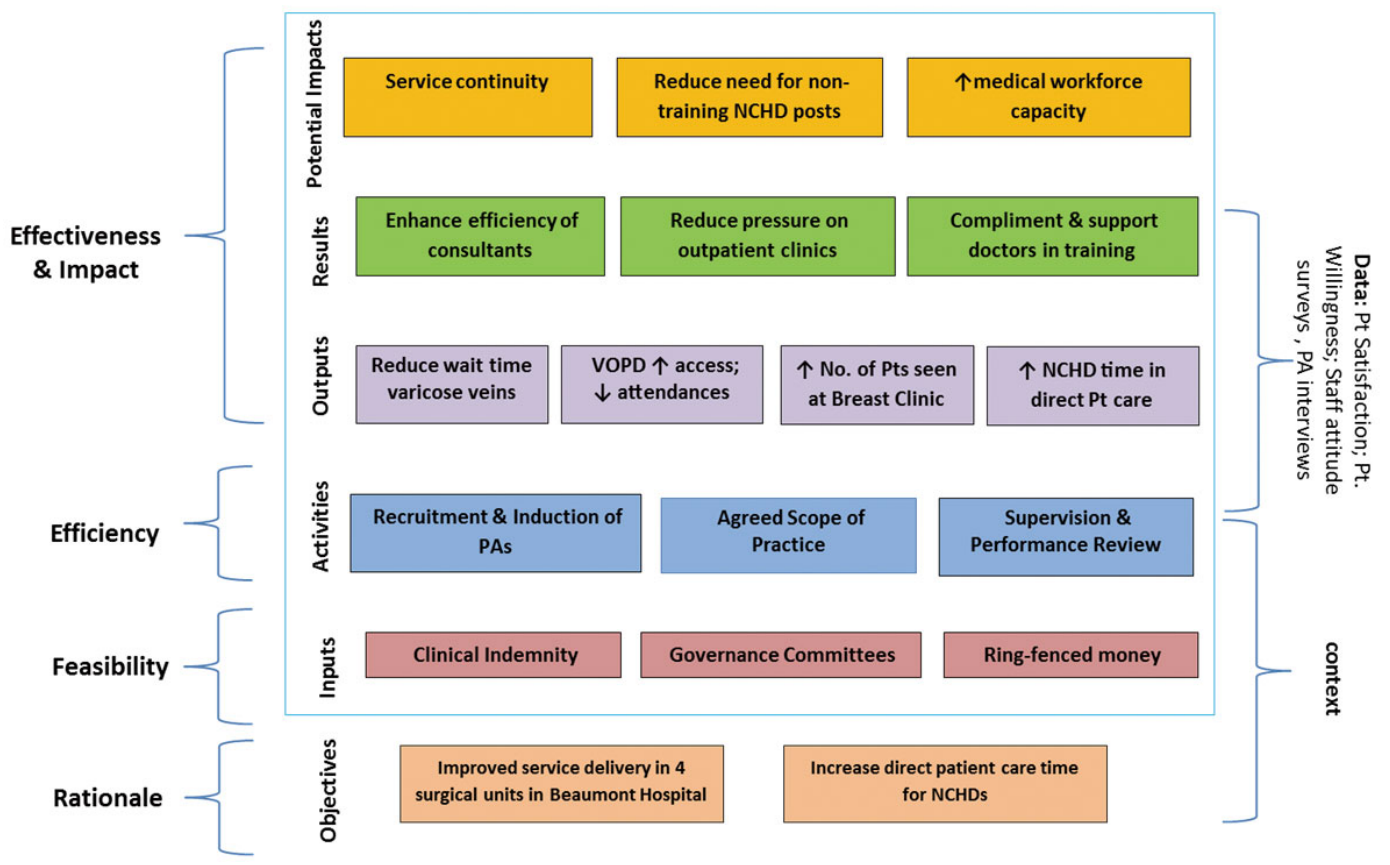

Figure 1. Summary Evaluation Findings

\subsection{Study setting}

The study setting was a large teaching hospital in the east of Ireland which has a bed capacity of 820 , and in excess of 3,000 staff. Beaumont Hospital in Dublin provides emergency and acute care services across 54 medical specialties to a community of 290,000 people. In addition, it is a Designated Cancer Centre and the Regional Treatment Centre for Ear, Nose and Throat, and Gastroenterology. The hospital serves as the National Referral Centre for Neurosurgery and Neurology, Renal Transplantation, and Cochlear Implantation.

The overall aim of this pilot project was to evaluate the contribution that the role of the PA could make to service delivery in four surgical units in a large teaching hospital.

The objectives of the project were:

- Improve service delivery in four surgical units at the hospital.

- Increase direct patient care time for doctors in training (NCHDs).

The scope of the pilot was small. One higher education sector in collaboration with a major teaching hospital piloted the introduction of the role by recruiting four PAs from North America to work in four designated surgical services. Two
PAs returned to North America after the first year leaving two PAs for the second year of the pilot project, one was recruited from the UK. The higher education sector with RCIS commenced a master's degree in Physician Associate Studies to coincide with the timeframe of the PA pilot project.

To satisfy the business case, clinical indemnity for the PAs was created. However, as the role did not exist in Ireland, they were excluded from prescribing medications or ordering ionising radiation. Such inputs provided the feasibility for the project (see Figure 1). Governance committees (see Figure 2) were set up to oversee the pilot and identify any issues at local level throughout the project.

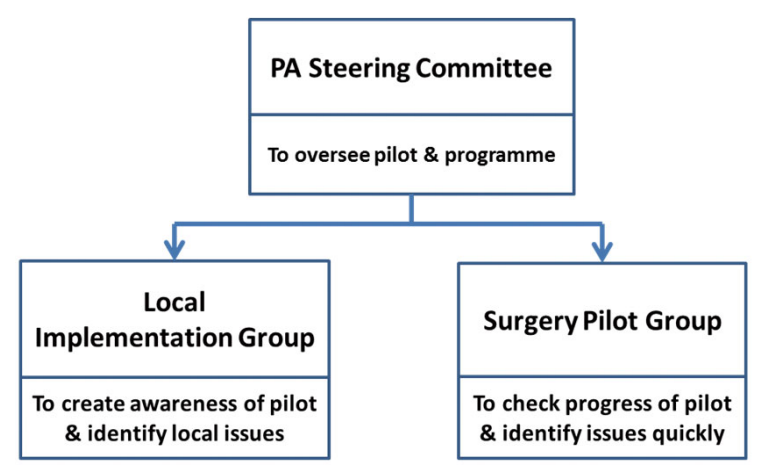

Figure 2. Governance of Pilot Project 


\subsection{Recruitment and informants}

The recruitment of four qualified PAs from North America in year one, was sanctioned by the Department of Health in Ireland. An agreed scope of practice was signed off by senior management in the hospital and supervision with performance reviews by supervising consultants was set up for the duration of the project.

\subsection{Data collection}

Evaluation of the initiative produced a number of outputs. Projects were set up to demonstrate the impact of the PA role within the surgical teams. Some projects demonstrated reduced wait time for services, including wait time for surgery for varicose veins. Others included the setting up of outpatient's visits, increased numbers of patients seen at a breast clinic and increasing the NCHD time in direct patient care. A sample of projects and their status update at the end of the pilot project is outlined in Table 1 .

Table 1. Projects carried out during the PA

\begin{tabular}{ll}
\hline Name of Project & Status/Update \\
\hline $\begin{array}{l}\text { Delivering a Virtual Outpatient } \\
\text { Colorectal Surgery Clinic }\end{array}$ & $\begin{array}{l}300 \text { patients were seen by the PA } \\
\text { during the pilot project. }\end{array}$ \\
$\begin{array}{l}\text { Review patient satisfaction with } \\
\text { colorectal service }\end{array}$ & $\begin{array}{l}\text { No difference in patient satisfaction if } \\
\text { seen by the PA or the doctor. }\end{array}$ \\
$\begin{array}{l}\text { Improving NCHD training } \\
\text { experience in theatre }\end{array}$ & $\begin{array}{l}\text { Increase in direct patient care time - } \\
\text { Time Motion study (Breast \& }\end{array}$ \\
$\begin{array}{l}\text { Decreasing a varicose vein } \\
\text { patient waiting time from clinic } \\
\text { to surgery }\end{array}$ & $\begin{array}{l}\text { Waiting time for varicose veins } \\
\text { decreased from 14 months to } 3 \\
\text { months. }\end{array}$ \\
$\begin{array}{l}\text { Increasing patient access to } \\
\text { breast clinic }\end{array}$ & $\begin{array}{l}\text { PA saw twice as many patients as the } \\
\text { NCHD. }\end{array}$ \\
\hline
\end{tabular}

These projects assessed impact of the PA role on the clinical teams.

While in Table 1 identified results such as enhanced efficiency, additional data were collected on other aspects of their utilisation. This included staff attitudes to the PA role, patient willingness to be seen by a $\mathrm{PA},{ }^{[21]}$ and patient satisfaction with the PA role where the role was piloted. An online survey to measure staff attitudes to the introduction of the PA role was set up at Time 1 -when staff were unfamiliar with the role, and again 2 years later (Time 2). An invite was sent to a random selection of healthcare staff via email by the Human Resources department in the hospital (ensuring that researchers were blinded to personal data). Each survey was coded and only the principal researcher, had access to codes in case of voluntary withdrawal. One-to-one interviews along with focus group interviews with the PAs on the pilot project were undertaken. In addition, key stakeholders within the hospital, were interviewed. Representatives from national and international bodies who were part of the project steering committee were also interviewed. These three groups formed the qualitative data for the study.

\subsection{Data analysis}

Analysis of the attitudes survey data was carried out via Excel spreadsheets and reported as Time 1 (response $-26 \%$ ) and Time 2 (response - 39\%) (see Table 2). Interview data, analysed by content analysis was presented to support or contradict quantitative data from the surveys. Separate oneto-one interviews with the PAs were analysed by content analysis and presented under the category of PA Role and System Issues (see Table 3).

\subsection{Ethics}

The study was approved by the Beaumont Hospital Ethics Committee. All participants gave consent for surveys and interviews. Each was informed that they could stop the interviews and withdraw from the study at any time, and that they were not required to answer all questions posed during the interview.

\section{RESUlts}

The demographics of the sample showed that $70 \%$ of respondents were in the 31-50 years' age group with $15 \%$ each in the 20-30 years and 51-64 years age groups. Response rate was $26 \%$ at time 1 and $39 \%$ at time 2. Females made up $77 \%$ of the sample and $72 \%$ had more than 11 years experience in healthcare. Of the sample tested $20 \%$ had worked with a PA. The sample spanned professions in nursing $(41 \%)$, medicine (28\%), physiotherapy ( $8 \%$ ), nutrition $(1 \%)$ with the remainder across "other" category. When asked if doctors and other healthcare professionals should be working with PAs in Ireland, $71 \%$ ticked yes.

\subsection{Hospital staff attitudes to the role of the PA}

Key findings from the staff attitudes on the introduction of the PA role at Time 1 suggest that $75 \%$ of the sample $(\mathrm{n}=$ 107) agree or strongly agree that working with a PA would allow doctors more time to focus on more complex clinical work. This result was similar in Time 2. In addition 63\% (Time 1) and $65 \%$ (Time 2) of the sample feel confident that clinical outcomes could be achieved with a PA working under the doctor as part of the multidisciplinary team. Staff strongly disagree at times 1 and 2 that management had made a case for the introduction of the PA role (stated as the change in the survey).

Responses to statements on working with a PA were mixed. Comparisons of responses before and at the end of the pilot project suggest an overall uncertainty about the role (see Table 2), in particular for statements 3 and 6 in Table 2. Because 
of small sample size, tests of statistical significance were not professions (doctors, nurses etc.) in overall responses. feasible. In addition there were no trends of note between

Table 2. Working with a PA

\begin{tabular}{|c|c|c|c|c|c|}
\hline & \multirow[t]{2}{*}{ Statement } & \multicolumn{2}{|c|}{$\begin{array}{l}\text { Start of Pilot Project }(n=107) \\
\text { Time } 1\end{array}$} & \multicolumn{2}{|c|}{$\begin{array}{l}\text { End of Pilot }(n=155) \\
\text { Time } 2\end{array}$} \\
\hline & & ${ }^{*} \mathrm{SD} / \mathrm{D}$ & ${ }^{* *}$ SA/A & SD/D & SA/A \\
\hline 1 & $\begin{array}{l}\text { I feel confident that doctors could delegate appropriately to a } \\
\text { Physician Associate }\end{array}$ & $17 \%$ & $67 \%$ & $20 \%$ & $61 \%$ \\
\hline 2 & $\begin{array}{l}\text { Working with a Physician Associate would allow doctors } \\
\text { more time for more complex clinical tasks }\end{array}$ & $7 \%$ & $75 \%$ & $8 \%$ & $73 \%$ \\
\hline 3 & $\begin{array}{l}\text { Doctors would need more training if they were to supervise a } \\
\text { Physician Associate }\end{array}$ & $30 \%$ & $50 \%$ & $31 \%$ & $49 \%$ \\
\hline 4 & $\begin{array}{l}\text { Working with a Physician Associate would allow doctors to } \\
\text { increase their management skills }\end{array}$ & $20 \%$ & $50 \%$ & $19 \%$ & $53 \%$ \\
\hline 5 & $\begin{array}{l}\text { Working with a Physician Associate would increase my } \\
\text { workload }\end{array}$ & $62 \%$ & $20 \%$ & $55 \%$ & $19 \%$ \\
\hline 6 & $\begin{array}{l}\text { Working with a Physician Associate would mean the } \\
\text { physician has less contact with clients }\end{array}$ & $42 \%$ & $37 \%$ & $39 \%$ & $38 \%$ \\
\hline 7 & $\begin{array}{l}\text { I feel confident that clinical outcomes could be achieved with } \\
\text { a Physician Associate working under the doctor as part of the } \\
\text { multidisciplinary team }\end{array}$ & $10 \%$ & $63 \%$ & $8 \%$ & $65 \%$ \\
\hline 8 & $\begin{array}{l}\text { Management made a case for the importance of this change } \\
\text { prior to implementation }\end{array}$ & $64 \%$ & $36 \%$ & $67 \%$ & $33 \%$ \\
\hline
\end{tabular}

"SD = Strongly Disagree; D = Disagree; ${ }^{* *}$ SA = Strongly Agree; $\mathrm{A}=$ Agree .

Although communication efforts were put in place to create awareness of the PA role, it was difficult for staff to appreciate how the PA might fit with the overall multidisciplinary team unless the PA was in their service. This finding was further validated with quotes from focus group interviews with Local Implementation Group (LIG) and steering committee members- (see Figure 2) and one-to-one interviews with healthcare staff, at the start and the completion of the pilot. For example:

Some improvements that we were talking about were better communications locally, with the local groups and staff they're interacting with. Better induction at local level.

I think so -the role and what they do. You see, they arrived and we didn't know what they could do. It was up to the individual consultants they work with who dictated what they were going to be doing and wouldn't be doing... (LIG member-Time 1)

The ongoing communication via smaller meetings and at Grand Rounds seems to have worked well to improve awareness of the project. Having PA students in the hospital also helps to keep the awareness of the role live. (LIG member -Time 2)

There needs to be consultation and letting staff know about the role, particularly staff working with these positions. High level communication is needed. Some staff went to their unions and to social media about something they didn't really know about. The whole communication piece is important and a parallel communication with staff about the role. (Steering Group member Time 1)

We have come a long way to get this project to this point and for staff to now understand what the PA role is about...this is good progress. However, with only 2 PA in place it is difficult to show much quantitative data so I think it is important to include qualitative data as well. (Steering Group member - Time 2)

There seemed to be a lack of communication about the pilot for healthcare staff working with the PAs, at the start of the pilot, as indicated below:

We weren't told anything before they started. 
From my understanding of the role they were there to take patient histories. That's all I knew about the role. Their purpose is to speed up patient waiting lists... We need clarification about their scope of practice and a good outline of their role. Who clinically governs them? If something goes wrong, who is responsible? We were just told as a, by the way, that there was someone joining the team. (Interviewee 3, Time 1)

However, following discussions in regular LIG meetings the PAs themselves drafted a communication leaflet for the NCHDs, which they received at handover, which seemed to lessen this communication gap, demonstrated in this quote from an NCHD who worked on the service with a PA:

I definitely notice that excess admin work is taken off my hands. It is difficult when rotating every six months to get to know processes and procedures in various hospitals so having one stable person on the team is great. Not only does [s] he look after the scheduling lists for theatre but [s] he is also available for clinical work if I need to take days off or leave. (Interviewee 7, Time 2)

Although there were information sessions in the Hospital system, along with computer screensavers and posters with photos of the PAs, communication did not reach all staff and was not sufficient according to the following participant:

I think there was a talk one day at lunch time about PAs coming to Beaumont but it didn't match my lunch break so I couldn't go. It can be difficult to get to talks like that - unless they're scheduled at a time that you're free. There was something on the computer screens but in general not a lot of information in the hospital was available. (Interviewee 4, Time 1)

However, one interviewee was positive about the role due to familiarity with it in the US and suggested:

They should be introduced across a team of consultants who know, understand and are familiar with the role. The way it was done in $\mathrm{X}$ was a good way to do it. (Interviewee 6, Time 1)

The interviewee went on to state the benefits of the role, from prior experience:

The PA was the constant - the face you recognised, who you remembered and who remembered you. There's such a high change-over of staff, the PA could offer continuity that other staff couldn't.... The other big benefit is in freeing up training time for junior doctors - particularly allowing them to spend more time in surgery - or to stay in surgery and not be called back to the ward. (Interviewee 6, Time 1)

The findings of the survey and interviews, at the start of the pilot project, highlighted the need to communicate the pilot project in many different formats and via as many opportunities as possible. The PA role was presented at medical grand rounds and surgical grand rounds on a number of occasions. Further information sessions were held via small group meetings across professions, e.g. nursing and allied healthcare professionals. These were organised by members of the LIG. The Business Manager for the surgical directorate also took up the Project Lead in the hospital to further communicate the role to colleagues regularly. Posters about the role of the PAs working in the hospital were distributed.

The quality and the continuity of care, particularly at the time of NCHD change-over in January and July (2017) improved, according to staff in the hospital, with the introduction of the PA role in the breast service. According to the nurse specialist in the service:

The PA has been a fantastic asset to the service. $\mathrm{X}$ is very knowledgeable, works really well with all the team and is always available. (Nurse Specialist Time 2)

Because of the high turnover of NCHDs it is fantastic to have the PA role to plan ahead for booking patients for theatre. The PA knows the patients well and the patients know $\mathrm{X}$ so we are delighted to work with the PA. (Nurse Specialist Time 2)

From the administration team perspective, feedback on the PA role is that they have confidence in the role and never have to follow-up as they know things get done. The PAs are organised and always contactable. However Nurse Specialist 1 said that there are some frustrations with the role because of the restrictions on ordering X-rays. She stated that:

Although the PA is first in the clinic she has to wait until medical colleagues arrive to see patients because the PA cannot order breast imaging. This is a huge frustration for the efficiency of the clinic. (Nurse Specialist 1 Time 2)

Feedback from the PAs recruited for the pilot project in the first year is presented in Table 3 . 
Table 3. Feedback from Physician Associates

PA Role
A.1 More communication and understanding of what a PA does
and their role within the hospital and the Irish Health Care
System is needed.
A.2 Some of the services need clearer plans regarding
utilisation of the PA role. Some NCHDs were unaware of the
role and its introduction to the hospital.

A.3 Some communication as to projected PA salary and why the PA was substituted for a non-training NCHD salary, as this created tension amongst the NCHDs and did not allow for PA role to be understood fully.

A.4 Hired as a surgical PA but allocation of PA into theatre is minimal due to NCHDs needing as much training time as possible.

A.5 Potential for multiple stakeholders having different ideas of the PA role - this can lead to confusion for the services and potential job dissatisfaction amongst the PAs.

A.6 Expected role of PA on pilot is highly administrative and clerical which does not correspond to PA training or job description.

A.7 More multidisciplinary education about the role prior to recruitment of PAs including their scope of practice.

A.8 Challenging in not being able to work to full potential due to regulatory issues.

\section{Systems Issues}

B.1 Lack of adequate hospital clerical support to facilitate the role (e.g. chart retrieval).

B.2 Having no Electronic Medical Record system makes for difficult location of patient information and records leading to wasted time tracking down charts.

B.3 Many departments within the Hospital seem to operate independently e.g. Radiology technician can cancel orders given by consultants. Ordering an echocardiogram requires walking to department with the request.

B.4 Unprepared regarding access to necessary electronic systems vital to role. Prolonged timeframe to resolve these issues as there was a lack of clarity/awareness around the PA role and whose responsibility it was to provide access.

B.5 PA Pilot unprepared regarding legal implications of signing forms within the hospital which requires a physician or surgeon's signature and is vital to the PA role e.g. Requesting Outpatient Bloods and Dictating Letters from Outpatients.

B.6 More support from HR in international transition. Some of the process can lead to confusion.

B.7 Boundary issues regarding phone calls/emails from hospital administrators or team members outside of normal working hours (on annual leave, evenings, weekends, etc.).

B.8 More induction to how hospital systems function and clarity on the roles of various NCHDs.
Many of the responses provided a difference in expectations, coming from a very different healthcare system in Canada and the United States. This data was helpful for those recruiting PAs for the first time.

\section{Discussion}

\subsection{Discussion of findings}

The findings from this project showed openness to the PA role in Ireland but a lack of awareness of the role itself. The preparation for the pilot project to test the role in the designated surgical directorate and the organisation could be improved. For the PAs who came from Canada and the US (in the second year) and the UK the differences in the healthcare system and the lack of awareness of the scope of the role was frustrating. PAs are providing care at significant levels of quality and quantity and their presence is enriching the response to the many challenges in healthcare delivery in the US. ${ }^{[22]}$ As of 2018 over 3200 PAs work as hospitalists in the US. ${ }^{[23]}$ A series of studies have not only shown their increased utilisation but how they benefited the efficiency of the hospital and postgraduate education service. ${ }^{\text {[24] }}$ Increasing clinical activity, such as patient throughput and increased productivity, has been reported as an impact of the PA role. ${ }^{[25,26]}$ Other studies ${ }^{[27-30]}$ conclude that PAs provide physician-equivalent levels of quality care.

While there were communication activities in advance of inaugurating the PA pilot, along with recruitment and induction activities when they started a lack of awareness among many staff about the PA role persisted. Introducing four PAs into an organisation employing, in excess of 3,000 staff, required more communication activities than anticipated. The PAs recruited for Year Two of the project, to replace two PAs who returned home, settled in quicker than the first four PAs.

Once the PA role was understood by colleagues there appeared to be good team role integration. The scope of practice was tailored to meet the skillset of the PA and the service requirements based on patient profile. It helped that the 
NCHDs and nurse specialists, in the services piloted, were positive about the PA role and the benefits it brought to the day-to-day organisation of the service. Based on this experience in Dublin, the following are recommendations for introductions of the PA role:

- Information and briefings to staff on the services where the PA will be working, well in advance, to ensure time for clarifications about the role and to reinforce how the role fits within the multidisciplinary team.

- Clarify the scope of practice of the PA at all local levels.

- Communicate the plan of supervision with the multidisciplinary team.

- Repeat as often as necessary to ensure all staff are included in the information distribution.

In this inauguration of the Physician Associate in Ireland, the interviews informed the pilot team on ways to communicate the project more effectively and how to create awareness of the role. At the same time a criticism of this data is its lack of generalisability, the findings do provide context and are relevant to other clinical settings where the introduction of the PA role might be considered. The interviews supported the survey data and provided explanations where needed.

The study provides insight into the PA role at a specific sample site in Ireland. When introducing the role in clinical settings, there are lessons learned for the integration and contribution of the PA. Evaluation of the PA role offers insights and considerations that warrant further exploration and research in light of any policy decisions or development of the role including regulation of the role. In making the business case for the pilot project it was suggested that the PA supports the recruiting and retaining of the right mix of staff and conforms to the WHO Global Code ${ }^{[31]}$ on the move to selfsufficiency. In addition, the project supports human resource planning with its focus on the transformation of workforce and organisational change using skill-mix initiatives. The restructuring and redeployment of existing workforce to new organisational structures and service delivery models is challenging. It also suggested that, while a new work rota had been adopted by the hospital in an attempt to meet the requirements of the EWTD, there were insufficient doctors to serve the needs of the surgical patients on the wards, in the intensive care unit, outpatients' clinics, endoscopy, or theatre. This has had an significant impact on continuity of patient care and service provision.

The PAs had some concerns about "deskilling", during the pilot, because they were unable to work to their full potential due to lack of regulation for the profession. This matches findings from Siggins Miller ${ }^{[32]}$ on the New Zealand Trial

Published by Sciedu Press around more communication needed in preparation for the PA role:

... it was not made clear to them (nurses and doctors) before the trial commenced when the PAs were commencing, what their role would be, or what they were legally allowed to do... some consultants didn't know PAs were being introduced to the hospital until after the PAs had started working, and this created some resistance from these individuals towards the PAs' (p.18).

Some recommendations at this point in the project were identified as the need to invest in robust stakeholder engagement across the hospital and the wider healthcare system. Lessons learned from other PA pilots such as limited understanding of the role ${ }^{[33]}$ in Australia, the need to develop stronger governance and regulatory frameworks for this profession in the $\mathrm{UK}^{[34]}$ and to explore cultural differences in PAs recruited from the US. ${ }^{[35,36]}$

The Australian health workforce is also evolving to meet the changing needs and shifting priorities of the contemporary health system. According to Wardle and colleagues ${ }^{[37]}$ task substitution and task delegation have long been a focus of Australian health policy and high-level tasks, once restricted to medical practitioners, have been promoted by Australian governments for task substitution.

A report on staffing in the NHS by Buchan and colleagues ${ }^{[38]}$ identified "the potential of physician associates" (p.28) as one of the six critical pressure points for the current healthcare workforce in England. Health Education England (HEE) ${ }^{[39]}$ states that their workforce planning process does not allow them to estimate demand for the PA role in a robust way. However, HEE acknowledge that the role is essential for trusts to address the service gaps created as more junior doctor posts are reconfigured to support GP expansion and the broadening of the Foundation Programme.

In considering the next steps of the PA in Ireland it is important to acknowledge the gaps in the healthcare system that cannot be filled by existing roles. These gaps can translate into opportunities and include:

(1) Capacity issues - there is an insufficient number of staff on medical teams with a global shortage of doctors. $^{[5-8]}$

(2) Continuity of Care - the doctors in training rota of three and six monthly rotations do not allow for continuity of care and encourage the potential for a decrease in quality and safety of patient care. PAs have the potential to meet this challenge. ${ }^{[30-33]}$ 
(3) Deployment of medical staff across teams when needed - there is no flexibility to allow for doctors in training to be moved across specialities during their medical training. The generalist education and training of the PA role allows for this flexibility and should be considered in workforce planning models. ${ }^{[34]}$

Challenges of evaluations where the PA role was introduced, for example, in the UK, ${ }^{[35,40]}$ Australia, ${ }^{[41]}$ and New Zealand $^{[42]}$ have all identified frustrations when regulation is not in place. Key medical tasks such as prescribing and ordering $\mathrm{x}$-rays delay the completion of the medical consultation and can restrict the flexibility, hence reducing efficiency and cost-effectiveness. However, progressing regulation of a new profession requires agreement at government level, as to where the role is best regulated. The options in Ireland are with CORU (the body which regulates allied health professionals) or the Irish Medical Council (IMC), which regulates doctors. The IMC is the most obvious for the PA role which has a reporting responsibility to the supervising consultant. In the UK the PA is registered with the Faculty of PAs within the Royal College of Physicians in London. Soon after this move the UK government announced their intent to regulate the profession. ${ }^{[42]}$ This move could influence how the Irish government acts with regards to regulating the PA role. However, the political climate is fraught with uncertainty due to BREXIT. Despite the vision of Sláintecare, ${ }^{[4]}$ there is a lack of confidence among the Irish public on how this health strategy will be implemented. From an economic standpoint the strategy needs significant investment to deliver its action points.

\subsection{Strengths and limitations}

When reviewing the findings of this evaluation report it is important to consider the strengths and limitations of the pilot design itself. The evaluation draws on multiple data sources to identify the attitudes of healthcare staff to the introduction of the PA role. It is a snapshot in time with a small sample and is context specific, based on the challenges in workforce planning, at that time. The logic model provided a guiding framework for the project and highlights key results and activities.

When using a mixed methods approach (quantitative and qualitative data) it is important to review the individual data collection methods. Data was collected for the staff survey at the start and at the end of the pilot project $(\mathrm{n}=107$, Time $1-26 \%$ response rate; and $\mathrm{n}=155$, Time $2-39 \%$ response rate). The survey instrument was amended from the questionnaire used in Australia, for exploring the attitudes of the introduction of a different healthcare role. While there are some limitations to a self-designed survey the response rates were acceptable and the survey provided some good insights into the acceptability and contribution of the PA role.

\section{Conclusions}

Two organisational constraints in moving the project forward are dependent on the speed at which the Irish Department of Health will make a decision on the next steps for the PA role. Delays in communicating the outcome of the project have been linked with national health scandals. The pace of change is slow, as other healthcare professions look to increase their staff numbers. However, with the PA role established in the US over fifty years ago, and ample evidence to show its impact, there is hope on the horizon and a willingness to support the introduction of this role into the wider healthcare system in Ireland. While this project was ring-fenced to a surgical directorate in one hospital there is scope for further studies to be carried out to explore how PA graduates in Ireland can impact across both primary and secondary care. There is also an opportunity to explore how the deployment of PAs could work in more rural hospital and GP centres, given the shortage of medical staffing in these areas.

\section{ACKNOWLEDGEMENTS}

The authors acknowledge the participation of staff and PAs who took part in the pilot project and Aisling Hegarty for interview data collection.

\section{CONFlicts OF InTEREST Disclosure}

The authors declare they have no conflicts of interest.

\section{REFERENCES}

[1] Health Consumer Powerhouse, Euro Health Consumer Index 2015. 2016: Marseillan, France.

[2] Health Insurance Authority, The Irish Healthcare System: An Historical and Comparative Review. 2018: Dublin, Health Insurance Authority.

[3] Turner B. Putting Ireland's health spending into perspective. The
Lancet. 2018; 391(March 3): 833-834. https : //doi.org/10.101 $6 / \mathrm{S} 0140-6736$ (18) 30461-6

[4] Houses of the Oireachtas, Sláintecare Report, Committee on the Future of Healthcare 2017: Dublin.

[5] Humphries N, Tyrell E, McAleese S, et al. A cycle of brain gain, waste and drain - a qualitative study of non-EU migrant doctors in Ireland. Human Resources for Health. 2013; 11(63): 1-10. https : 
//doi.org/10.1186/1478-4491-11-63

[6] Humphries N, McAlesse S, Matthews A, et al. Emigration is a matter of self-preservation. The working conditions . . . are killing us slowly': qualitative insights into health professional emigration from Ireland. Human Resources for Health. 2015; 13: 1-13. https://doi.org/10.1186/s12960-015-0022-6

[7] Brugha RF, Cronin F, Clarke N. Retaining our Doctors Medical Workforce Evidence, 2013-18. Full report. 2018: Dublin.

[8] OECD. Health at a glance: OECD Europe 2015.

[9] Department of Health, European Working Time Directive. [cited 2018 09.11.18].

[10] Cawley JF, Hooker RS. Determinants of the physician assistant/associate concept in global health systems. International Journal of Healthcare. 2018; 4(1): 50-60. https ://doi .org/10.5430/ij h. v4n 1 p50

[11] Steinbrook R. The debate over residents' work hours. New England Journal of Medicine. 2002; 347(16): 1296-1302. PMid:12393837. https://doi.org/10.1056/NEJMhpr022383

[12] NDTP, Sixth Annual Assessment of NCHD Posts 2015-2016. 2016a: Dublin.

[13] NDTP. Planning the Medical Workforce of the Future; Strategic Medical Workforce Planning for Ireland. 2016b: Dublin.

[14] (WHO), W.H.O., User's Guide to the WHO Global Code of Practice on the International Recruitment of Health Personnel. (2012): Geneva.

[15] Bidwell P, Humphries N, Dicker P, et al. The national and international implications of a decade of doctor migration in the Irish context. Health Policy. 2013; 110: 29-38. PMid:23253361. https://doi.org/10.1016/j.healthpol.2012.10.002

[16] Humphries N, Brugha R, McGee H. Nurse migration and health workforce planning: Ireland as illustrative of international challenges. Health Policy. 2012; 107(1): 44-53. PMid:22818519. https : //doi.org/10.1016/j.healthpol.2012.06.007

[17] Virtanen P, Uusikylä P. Exploring the missing links between cause and effect: a conceptual framework for understanding micro-macro conversations in programme evaluation. Evaluation and program planning. 2004; 10(1): 77-91. https ://doi .org/10.1177/1356 389004043136

[18] Cousins JB, Aubry T. Roles for government in evaluation quality assurance. 2006: Ottawa.

[19] Cohen L, Mannion L, Morrison K. Research Methods in Education. 7th ed. 2011, London: Routledge.

[20] Brousselle A, Champagne F. Program theory evaluation: logic analysis. Evaluation Program Planning. 2011; 34(2): 69-78. https: //doi.org/10.1016/j . evalprogplan.2010.04.001

[21] Joyce P, Arnett R, Hill A, et al. Patient Willingness to be Seen by a Physician Associate in Ireland. International Journal of Healthcare. 2018; 4(2): 41-50. https: //doi.org/10.5430/ijh.v4n2p41

[22] Dehn RW, Everett C, Hooker RS. Research on the PA profession: The medical model shifts. Journal of the American Academy of Physician Assistants. 2017; 30(5): 33-42. PMid:28441218. https : //doi.org/10.1097/01.JAA.0000515548.76484.39

[23] National Commission on Certification of Physician Assistants, Inc. 2017 Statistical Profile of Certified Physician Assistants: An Annual Report of the National Commission on Certification of Physician Assistants. 2018; Available from: http://www.nccpa.net/rese archAccessed04/02/2019

[24] Roberts S, Howarth S, Millott H, et al. Experience of the impact of physician associates on postgraduate medical training: A mixed methods exploratory study. Clinical Medicine. 2019; 19(1): 4-10. PMid:30651237. https ://doi.org/10.7861/clinmedicine.1 9-1-4

Published by Sciedu Press
[25] Ducharme J, Alder RJ, Pelletier C, et al. The impact on patient flow after the integration of nurse practitioners and physician assistants in 6 Ontario emergency departments. Canadian Journal of Emergency Medicine. 2009; 11(5): 455-461. https://doi.org/10.1017/S1 481803500011659

[26] Dies N, Rashid S, Shandling M, et al. Physician assistants reduce resident workload and improve care in an academic surgical setting. Journal of the American Academy of Physician Assistants. 2016; 29(2): 41-46. PMid:26818645. https://doi.org/10.1097/01 . JAA. 0000476214.34937 .50

[27] Hooker RS, Cipher D. Physician assistant and nurse practitioner prescribing: 1997-2002. Journal of Rural Health. 2005; 21(4): 355-360. https://doi.org/10.1111/j.1748-0361.2005.tb00107.x

[28] Agarwal A, Zhang W, Kuo Y, et al. Process and Outcome Measures among COPD Patients with a Hospitalization Cared for by an Advance Practice Provider or Primary Care Physician. PLoS ONE. 2016 11(2). https://doi.org/10.1371/journal.pone.0148522

[29] Bloemhoff A, Schoonhoven L, de Kreek AJL, et al. Solo emergency care by a physician assistant versus an ambulance nurse: a cross-sectional document study. Scandinavian Journal of Trauma, Resuscitation and Emergency Medicine. 2016; 24(86): 1-8. https : //doi.org/10.1186/s13049-016-0279-3

[30] Kurtzman ET, Barnow B. A Comparison of Nurse Practitioners, Physician Assistants, and Primary Care Physicians' Patterns of Practice and Quality of Care in Health Centers. Medical Care. 2017; 55(6): 615-622. PMid:28234756. https://doi.org/10.1097/ML R. 0000000000000689

[31] World Health Organisation, User's Guide to the WHO Global Code of Practice on the International Recruitment of Health Personnel. 2012: Geneva.

[32] Miller M, Siggins I, Thomson N, et al. The potential role of Physician Assistants in the Australian context. Healthworkforce, 2011.

[33] Health Workforce Australia, Evaluation of Physician Assistants in SA Hospitals. 2010: Adelaide: Department of Health, Australia.

[34] Drennan V, Halter M, Levenson R, et al. Physician assistants in English general practice: a qualitative study of the employers' viewpoint. Journal of Health Service Research Policy. 2011; 16: 75-80. PMid:21389060. https://doi.org/10.1258/jhsrp. 2010.010 061

[35] Farmer J, Currie M, Hyman J, et al. Evaluation of physician assistants in National Health Service Scotland. Scottish Medical Journal. 2011; 56(3): 130-134. PMid:21873716. https://doi.org/10.1258/sm j. 2011.011109

[36] Appleton-Dyer S, Field A, Dale-Gandar L, et al. Phase 11 of the Physician Assistant Demonstrations Evaluation Report. 2015. New Zealand: Health Workforce New Zealand.

[37] Wardle JL, Sibbritt D, Broom A, et al. Is Health Practitioner Regulation Keeping Pace with the Changing Practitioner and Health-Care Landscape? An Australian Perspective. Frontiers in Public Health. 2016; 4(91): 1-5. https : //doi .org/10.3389/fpubh. 2016.000 91

[38] Buchan J, Seccombe I, Charlesworth A. Staffing matters; funding concerns. Workforce profile and trends in the Engligh NHS. 2016 London.

[39] Health Education England, Investing in people for health and health care. Workforce plan for England. 2015: HEE, London.

[40] Drennan VM, Halter M, Brearley S, et al. Investigating the contribution of physician assistants to primary care in England: a mixedmethods study. Health Services and Delivery Research. 2014; 2(16) https://doi.org/10.3310/hsdr02160 
[41] Miller M, Siggins I, Thomson N, et al. The potential role of Physician Assistants in the Australian context. Health Workforce Australia. 2011.
[42] Ritsema TS, Roberts KA, Watkins LS. Explosive Growth in British Physician Associate Education Since 2008. The Journal of Physician Assistant Education. 2019; 30(1): 57-60. PMid:30676532. https://doi.org/10.1097/JPA.0000000000000233 